\title{
Endoscopic study on the intubation of the „pathological larynx“. Applications in anesthesia. Results
}

\author{
Studiu endoscopic privind intubaţia „laringelui patologic“. \\ Aplicaţii în anestezie. Rezultate
}

\author{
Bogdan Moscaliuc ${ }^{1}$, Viorel Zainea ${ }^{1,2}$, Răzvan Hainăroşie ${ }^{1,2}$, Cosmin Nisipaşus ${ }^{1,3}$ \\ ${ }^{1}$ Institutul de Fonoaudiologie şi Chirurgie Funcţională ORL „Prof. Dr. Dorin Hociotă“, Bucureşti, România \\ ¿UMF "Carol Davila“, Bucureşti, România \\ 3Universitatea "Titu Maiorescu“, Bucureşti, România
}

\begin{abstract}
In this prospective, observational, analytical and statistical study we identified the clinical situations in which an oro-tracheal intubation on the pathological larynx is necessary and the necessary conduct in this case. Descriptive analysis of clinical cases selected according to various parameters, calculation of fundamental statistical parameters, their graphical representation was performed using Excel, using the commands Function Statistical, Chart, Picot Tables, Data Analysis. Performing qualitative statistical tests were performed using the exact Fisher test (the exact variant of the Chi-square test). Of all the means of control and facilitation of the oro-tracheal intubation used, the rhino-pharyngeal-laryngo-tracheal fibroscopes were noted. Intra-laryngeal lesions that define „pathological larynx" represented in our study $88 \%$ of patients. The risk of difficult orotracheal intubation (OTI) is due to the presence of pathological larynx.

Keywords: oro-traheal intubation, pathological larynx, rino-faringo-laryngo-traheal fibroscopes

\section{REZUMAT}

În acest studiu prospectiv, observaţional, analitic şi statistic am identificat situaţiile clinice în care este necesară o intubaţie oro-traheală pe laringe patologic şi a conduitei necesare în acest caz. Analiza descriptivă a cazurilor clinice selectate în funcţie de diverşi parametri, calcularea parametrilor statistic fundamentali, reprezentarea lor grafică a fost efectuată cu ajutorul programului Excel, cu ajutorul comenzilor Function Statistical, Chart, Picot Tables, Data Analysis. Realizarea testelor statistice calitative au fost efectuate cu ajutorul testului Fisher exact (varianta exactă a testului Chi-pătrat). Dintre toate mijloacele de control şi facilitare a intubaţiei oro-traheale folosite, s-au remarcat fibroscoapele rino-faringo-laringo-traheale. Leziunile intralaringiene ce definesc „laringele patologic" au reprezentat în studiul nostru un procent de $88 \%$. Riscul de intubaţie oro-traheală (IOT) dificilă este dat de prezenţa laringelui patologic.
\end{abstract}

Cuvinte cheie: intubaţie oro-traheală, laringe patologic, fibroscoape rino-faringo-laringotraheale

\section{INTRODUCERE}

Medicul ATI se confruntă zilnic cu manevra de intubaţie oro-traheală. Această manevră este efec- tuată într-o varietate mare de situaţii clinice: intervenţii chirurgicale programate sau în urgenţă; urgențe medicale de natură diversă (stop cardiorespirator, insuficienţă respiratorie acută, protecţia 
căilor respiratorii) la pacienţi cu o mare variabilitate a vârstei, a conformaţiei şi a patologiilor. Societatea Americană de Anestezie încearcă definirea căii aeriene dificile ca fiind momentul în care un medic anestezist întâmpină dificultăţi în ventilarea pacientului cu mască facială, întâmpină dificultăţi în intubare orotraheală sau în ambele situaţii (1). În urma unui studiu efectuat de Colegiul Regal al Anesteziştilor şi a Societăţii de Căi Aeriene Dificile, pe o perioadă de 12 luni în toate spitalele din Marea Britanie, s-a identificat că pacienţii cu o patologie de cap şi gât reprezintă $40 \%$ din totalul complicaţiilor majore la intubaţie (hipoxie, moarte, traheostoma de urgență) (2). O metaanaliză recentă arată că intubaţia dificilă are o incidenţă de 5,8\% la pacienţii fără o cale aeriană patologică (3). Complicaţiile minore date de calea aeriană dificilă apar aproximativ la fiecare 40 pacienţi $(4,5)$. Complicaţiile majore date de calea aeriană dificilă apar aproximativ la fiecare 22.000 pacienţi $(5,6)$. Manevra de intubat intersectează laringele, un organ al fonaţiei, un duct aerian şi sfincteric ce se întinde de la nivelul limbii până la trahee. Este situat în opoziţie faţă de vertebrele cervicale 3-6 la bărbaţi, ceva mai sus la copii şi femei (7). Laringe patologic înseamnă laringe cu leziuni sau disfuncţii care fac dificilă procedura de intubaţie oro-traheală fie prin obstrucţionarea acesteia, fie prin posibilitatea producerii unor leziuni secundare endo şi exo laringiene. Noţiunea de laringe patologic include: leziuni benigne, leziuni maligne laringiene şi hipo-faringo-laringiene, leziuni neurologice, sindroame compresive cervicale (adenopatii, tumori), sindroame compresive perilaringiene, malformaţii sau schele posttraumatice, tumorile planşeului bucal şi baza limbii, pacienţii obezi prezentând comorbidităţi conexe (8). Mijloacele tehnice de expunere video a laringelui în vederea intubaţiei oro-traheale (IOT) sunt reprezentate de videolaringoscoape şi de fibroscop.

\section{SCOPUL STUDIULUI}

Identificarea situaţiilor clinice în care este necesară o intubaţie oro-traheală pe laringe patologic şi a conduitei necesare în acest caz.

\section{MATERIAL ŞI METODĂ}

Studiu prospectiv, observaţional, analitic şi statistic, bazat pe videoendoscopie laringiană şi de perimetru anatomic, pe durata 01.01.2011-06.07.2016, desfăşurat în secţiile de profil Chirurgie Generală, ORL, Ginecologie în Unităţile Spitaliceşti SUU Elias, Institutul de Fonoaudiologie şi Chirurgie Funcţi- onală ORL „Prof. Dr. Hociotă““, Spitalul „Regina Maria“. Lotul de studiu a inclus 1.031 intubaţii orotraheale (IOT), dintre care am selecţionat 52 cazuri clinice relevante pentru studiu şi contextul de intubaţie dificilă. Discutăm de un procent de aproximativ $5 \%$ intubaţii orotraheale pe ,laringe patologic“.

Am preluat datele folosind programul Microsoft Excel Macrosoft Corp., (SUA), împreună cu licenţa XLSTAT pentru MS Excel (Adinsoft SARL, Paris, Franţa). Am stocat informaţiile în fişiere Microsoft Excel, ulterior am prelucrat statistic datele.

Analiza descriptivă a cazurilor clinice selectate în funcţie de diverşi parametri, calcularea parametrilor statistic fundamentali şi reprezentarea lor grafică au fost efectuate cu ajutorul programului Excel, cu ajutorul comenzilor Function Statistical, Chart, Picot Tables, Data Analysis.

Testele statistice calitative au fost efectuate cu ajutorul testului Fisher exact (varianta exactă a testului Chi-pătrat). Progresul semnificaţiei statistice a fost de $\mathrm{P}<0,05$. Dacă $\mathrm{P}>0,05$, diferenţele nu sunt semnificative statistic.

\section{REZULTATE}

Leziunile intralaringiene ce definesc „laringe patologic" au reprezentat în studiul nostru un procent de $88 \%$.Leziunile extralaringiene ce fac dificilă identificarea laringelui determinând intubaţie oro-traheală (IOT) dificilă au fost în procent de $2 \%$. $10 \%$ reprezintă alte leziuni.

Mijloacele tehnologice de expunere a laringelui în vederea intubaţiei oro-traheale (IOT) pentru a preveni o intubaţie oro-traheală (IOT) dificilă sau a o finaliza au fost în studiul nostru următoarele: 1 . Fibra optică 64\%; 2. C-MAC (videolaringoscop cu lamă curbă); 2\% 3. Laringoscop Macintosh (laringoscop cu lamă de intubat curbă utilizat în intubaţia clasică) $23 \%$; 4. Pacienţi temporizaţi şi traheostomizaţi $11 \%$;

Dintre toate mijloacele de control şi facilitare a intubatiei oro-traheale folosite s-au remarcat: fiabilitatea, multidisponibilitatea şi anduranţa în folosire, a unor fibroscoape rino-faringo-laringotraheale ce au creat oportunitatea abordării filierii respiratorii în diverse situatii clinice.

Principalele leziuni ce definesc ,laringele patologic" ce au creat situaţii de intubaţie oro-traheală (IOT) dificile au fost: 1 . Leziunile de natură obstructivă $60 \%$; 2 . Leziuni de natura conformaţională $17 \%$; 3. Leziuni de natură neurologică $11 \%$; 4 . Leziuni de natură obstructivă şi conformaţională $10 \%$; 5 . Leziuni datorate bolii de reflux gastro-esofagian $2 \%$; 
Principalele contexte clinice au fost: prezentarea pacientului în vederea unei intervenţii chirurgicale de urgență sau programată; prezentarea pacientului în vederea unui consult de specialitate ce necesită ulterior o intervenţie chirurgicală; resuscitare cardio-respiratorie în stopul cardio-respirator; intubaţie la pacienţi cu leziuni date de aburi, foc (arsuri termice şi chimice);

Am identificat o distribuţie majoritară a pacienţilor cu vârste de 40-60 ani, cu un procent de 36,5\% femei şi $63,5 \%$ bărbaţi.

Vârsta predominantă a femeilor a fost de 40-50 ani, iar a bărbaţilor - de 50-60 ani.

Pacienţii au prezentat în proporţie de $54 \%$ antecedente ORL cunoscute, identificate în urma examenului preanestezic, faţă de $46 \%$ care nu aveau cunoştinţă de ele.

Pacienţii au prezentat în proporţie de $69 \%$ alte APP, faţă de $31 \%$ care nu prezentau.

Motivul prezentării a fost în 50\% urgenţă, 7\% dintre pacienţi prezentându-se pentru intervenţie chirurgicală.

Repartiţia dintre pacienţii fumători/nefumători a fost de $48 \%$ / $52 \%$.

Evaluarea riscului anestezic identifică: în funcţie de ASA - I. 22,42\%; II. 7,13\% ; III. 18,35\%; IV. 24\%; în funcţie de Mallampati - I. 13,25\%; II. $21,40 \%$; III. 5,10\%; IV. 9,17\%.

TABEL 1. Analiză statistică între cele 2 loturi în functie de sex

\begin{tabular}{|l|c|c|c|c|}
\hline & & Femei & Bărbați & Total \\
\hline Lot 1 - fără IOT flexibilă & $\mathrm{N}$ & 8 & 14 & 22 \\
\hline Lot 2 - cu IOT flexibilă & $\mathrm{M}$ & 11 & 19 & 30 \\
\hline Total lot: & & $\mathbf{1 9}$ & $\mathbf{3 3}$ & $\mathbf{5 2}$ \\
\hline $\begin{array}{l}\text { Test Fisher (exact): P = 1 } \\
\text { Nu există diferențe semnificative statistic între cele două loturi } \\
\text { în funcție de sex. }\end{array}$
\end{tabular}

Valoarea testului Fisher $\mathrm{P}=1$ ne indică faptul că nu există diferenţe semnificative statistic între cele două loturi în funcţie de sex.

TABEL 2. Analiză statistică între cele 2 loturi în funcție de antecedente ORL cunoscute

\begin{tabular}{|l|c|c|c|c|}
\hline & & ORL & NU & Total \\
\hline Lot 1 - fără IOT flexibilă & $\mathrm{N}$ & 5 & 17 & 22 \\
\hline Lot 2 - cu IOT flexibilă & $\mathrm{M}$ & 16 & 14 & 30 \\
\hline Total lot: & $\mathbf{2 1}$ & $\mathbf{3 1}$ & $\mathbf{5 2}$ \\
\hline $\begin{array}{l}\text { Test Fisher (exact): P = 0,044 } \\
\text { Există diferențe semnificative statistic între cele două loturi în } \\
\text { funcție de antecedente ORL cunoscute. }\end{array}$
\end{tabular}

Valoarea testului Fisher $\mathrm{P}=0,044$ ne indică faptul că există diferenţe semnificative între cele două loturi în funcţie de antecedentele ORL cunoscute.
TABEL 3. Analiză statistică între cele 2 loturi în funcție de APP cunoscute

\begin{tabular}{|c|c|c|c|c|}
\hline & & Cu APP & Fără AP & Total \\
\hline Lot 1 - fără IOT flexibilă & $\mathrm{N}$ & 14 & 8 & 22 \\
\hline Lot 2 - cu IOT flexibilă & $\mathrm{M}$ & 23 & 7 & 30 \\
\hline Total lot: & & 37 & 15 & 52 \\
\hline
\end{tabular}

Valoarea testului Fisher $\mathrm{P}=0,362$ ne indică faptul că nu există diferențe semnificative statistic între cele două loturi în funcţie de APP cunoscute.

TABEL 4. Analiză statistică între cele 2 loturi în funcție de laringele patologic

\begin{tabular}{|l|c|c|c|c|}
\hline & & $\begin{array}{c}\text { Laringe } \\
\text { patologic }\end{array}$ & $\begin{array}{c}\text { Fără } \\
\text { patologie }\end{array}$ & Total \\
\hline Lot 1 - fără IOT flexibilă & $\mathrm{N}$ & 15 & 7 & 22 \\
\hline Lot 2 - cu IOT flexibilă & $\mathrm{M}$ & 18 & 12 & 30 \\
\hline Total lot: & & $\mathbf{4 3}$ & $\mathbf{9}$ & $\mathbf{5 2}$ \\
\hline $\begin{array}{l}\text { Test Fisher (exact): P = 0,0267 } \\
\text { Există diferențe semnificative statistic între cele două loturi în } \\
\text { funcție de laringele patologic. }\end{array}$
\end{tabular}

Valoarea testului Fisher $\mathrm{P}=0,0267$ ne indică faptul că există diferenţe statistice între cele două loturi în funcţie de laringele patologic.

TABEL 5. Analiză statistică între cele 2 loturi în funcție de urgența cazului

\begin{tabular}{|c|c|c|c|c|}
\hline & & $\begin{array}{l}\text { Urgență } \\
\text { DA }\end{array}$ & $\begin{array}{c}\text { Urgență } \\
\text { NU }\end{array}$ & Total \\
\hline Lot 1 - fără IOT flexibilă & $\mathrm{N}$ & 10 & 12 & 22 \\
\hline Lot 2 - cu IOT flexibilă & $\mathrm{M}$ & 16 & 14 & 30 \\
\hline Total lot: & & 26 & 26 & 52 \\
\hline
\end{tabular}

Valoarea testului Fisher $\mathrm{P}=0,589$ ne indică faptul că nu există diferenţe semnificative statistic între cele două loturi în funcţie de urgenţa cazului.

TABEL 6. Analiză statistică între cele 2 loturi în funcție de fumat

\begin{tabular}{|c|c|c|c|c|}
\hline & & Fumători & Nefumători & Total \\
\hline Lot 1 - fără IOT flexibilă & $\mathrm{N}$ & 8 & 14 & 22 \\
\hline Lot 2 - cu IOT flexibilă & $\mathrm{M}$ & 18 & 12 & 30 \\
\hline Total lot: & & 26 & 26 & 52 \\
\hline
\end{tabular}

Valoarea testului Fisher $\mathrm{P}=0,104$ ne indică faptul că nu există diferenţe semnificative statistic între cele două loturi în funcţie de fumat. 
TABEL 7. Analiză statistică între cele 2 loturi în funcție de apariția la 12-24 h de leziuni postintubație

\begin{tabular}{|l|c|c|c|c|}
\hline & & $\begin{array}{c}\text { Cu } \\
\text { leziuni }\end{array}$ & $\begin{array}{c}\text { Fără } \\
\text { leziuni }\end{array}$ & Total \\
\hline Lot 1 - fără IOT flexibilă & $\mathrm{N}$ & 12 & 10 & 22 \\
\hline Lot 2 - cu IOT flexibilă & $\mathrm{M}$ & $\mathbf{2 3}$ & $\mathbf{7}$ & 30 \\
\hline Total lot: & & $\mathbf{3 5}$ & $\mathbf{1 7}$ & $\mathbf{5 2}$ \\
\hline
\end{tabular}

Test Fisher (exact): $\mathrm{P}=0,135$

Nu există diferențe semnificative statistic între cele două loturi în funcție de apariția la 12-24 ore de leziuni postintubație.

Valoarea testului Fisher $\mathrm{P}=0,135$ ne indică faptul că nu există diferenţe semnificative statistic între cele două loturi în funcţie de apariţia la 12-24 ore de leziuni postintubaţie.

TABEL 8. Analiză statistică între cele 2 loturi în funcție de laringele patologic

\begin{tabular}{|l|c|c|c|c|}
\hline & & $\begin{array}{c}\text { Laringe } \\
\text { patologic }\end{array}$ & $\begin{array}{c}\text { Fără } \\
\text { patologie }\end{array}$ & Total \\
\hline Lot 1 - fără IOT flexibilă & $\mathrm{N}$ & 15 & 7 & 22 \\
\hline Lot 2 - cu IOT flexibilă & $\mathrm{M}$ & 18 & 12 & 30 \\
\hline Total lot: & & $\mathbf{4 3}$ & $\mathbf{9}$ & $\mathbf{5 2}$ \\
\hline $\begin{array}{l}\text { Test Fisher (exact): P }=0,0267 \\
\text { Există diferențe semnificative statistic între cele două loturi în } \\
\text { funcție de laringele patologic. }\end{array}$
\end{tabular}

Valoarea testului Fisher $\mathrm{P}=0,0267$ ne indică faptul că există diferenţe statistice între cele două loturi în funcţie de laringele patologic.

În studiul prezent NU se identifică risc de intubaţie oro-traheală (IOT) dificilă în urma scorului Mallampati; riscul de intubaţie oro-traheală (IOT) dificilă este dat de laringele patologic.

Clasificarea sondelor pentru intubaţie oro-traheală (IOT) în funcţie de material a fost: PVC 67\% (28 sonde); silicon 33\% (14 sonde).

Clasificarea sondelor pentru intubaţie oro-traheală (IOT) în funcţie de tipul lor a fost: normală $-71 \%$ (30 sonde); flexometalică - 29\% (12 sonde).

Clasificarea sondelor pentru intubaţie oro-traheală (IOT) în funcţie de diametrul lor a fost: intubaţie oro-traheală (IOT) pe fibră optică - majoritar diametrul $7 \mathrm{~mm}$; intubaţie oro-traheală (IOT) cu laringoscop Macintosh - majoritar diametrul 8 $\mathrm{mm}$; intubaţie oro-traheală (IOT) cu laringoscop C$\mathrm{MAC}$ - diametrul $7 \mathrm{~mm}$.

\section{DISCUȚII}

Ca rezultat al studiului observaţional, am propus un protocol actualizat ale cărui obiective completează protocolul actual utilizat preoperator de medicul anestezist.

Trebuie să avem conduită preventivă şi eficientă privind IOT pe laringele patologic cu care aneste- zistul se confruntă în aproximativ 5\% dintre cazuri, dintre care unele sunt urgenţe majore, în concordanţă cu datele din literatura de specialitate (9).

Videofibroscopul rino-faringo-laringo-traheal a prezentat cea mai mare versatilitate în abordarea filierei respiratorii în diverse situaţii clinice. Dintre toate fibroscoapele rino-faringo-laringo-traheale, le-am utilizat cel mai frecvent pe cele cu grad de libertate uniplan cu $90^{\circ}$ şi $120^{\circ}$.

Studii de început au demonstrat eficienţa unei pregătiri treptate, iniţial în situaţii normale, mediu controlat, ulterior trecerea la pacienţi cu cale aeriană dificilă (10). Sunt date care arată că iniţial curba de învăţare este rapidă, manevra de intubaţie pe fibră optică fiind însuşită după 10 manevre de intubat pe cale aeriană normală la pacienţi anesteziaţi general (11). Alte studii arată că rezultate similare se obţin şi în cazul învăţării pe pacienţi anesteziaţi general şi curarizaţi, cât şi la pacienţi necurarizaţi $(12,13)$.

$\mathrm{Nu}$ există un consens în ceea ce priveşte cea mai bună tehnică de învăţare a manevrei de intubat pe fibră optică, unii considerând că cei mai în măsură să efectueze manevra sunt cei ce o practică în mod curent (14).

În funcţie de tipul, design-ul, flexibilitatea sondei de intubat, un studiu a demonstrat o rată de succes a intubaţiei de $66 \%$ utilizând sondă de intubat standard, în acord cu studiul nostru de $71 \%$; o uşoară neconcordanţă apare în cazul utilizării sondelor de intubat flexometalice cu un procent de $40 \%$ versus $29 \%$ (15).

$\mathrm{Nu}$ am identificat leziuni dentare în cadrul studiului, în concordanţă şi cu alt studiu (16). Conform altei lucrări, pacienţii ce prezintă risc de leziuni dentare sau au lucrări dentare sunt candidaţi la intubaţia pe fibră optică (17).

Ca şi în cazul altor studii, nu au apărut complicaţii secundare semnificative cum ar fi disfonie şi usturime gât $(18,19)$.

\section{CONCLUZII}

Studiul nostru pledează pentru calitatea manevrei IOT evocând: diversitatea cazuistică ce poate induce o IOT dificilă; consecinţele dramatice ale nefinalizării IOT; crearea de leziuni secundare iatrogene în contextul unor analize superficiale, incomplete sau complexe ale unor leziuni endo-laringiene sau ale perimetrului laringian.

Studiul pledează pentru utilizarea tuturor mijloacelor moderne de expunere a filierei faringo-laringo-traheală, a perimetrului laringian. Avem în vedere tehnologiile de magnificare şi expunere a laringelui (videolaringoscop, videofibroscop). 


\section{BIBLIOGRAFIE}

1. Practice guidelines for management of the difficult airway: An updated report by the American Society of Anesthesiologists Task Force on Management of the Difficult Airway. American Society of Anesthesiologists Task Force on Management of the Difficult Airway. Anesthesiology. 2003;98(5):1269-77.

2. Cook TM, MacDougall-Davis SR. Complications and failure of airway management. British Journal of Anaesthesia 2012;109(suppl 1):i68i85.

3. Shiga T, Wajima Z, Inoue T, Sakamoto A. Predicting difficult intubation in apparently normal patients: A meta-analysis of bedside screening test performance. Anesthesiology 2005;103(2):429-37.

4. Cook TM, Woodall N, Frerk C. Major complications of airway management in the UK: Results of the Fourth National Audit Project of the Royal College of Anaesthetists and the Difficult Airway Society. Part 1: Anesthesia. Br J Anaesth. 2011;106:617-31.

5. El-Boghdadly K, Ahmad I. Anaesthesia for the difficult airway. Journal of ENT Masterclass 2015;8(1):118-22.

6. Cook TM, Woodall N, Harper J, Benger J. Major complications of airway management in the UK: Results of the Fourth National Audit Project of the Royal College of Anaesthetists and the Difficult Airway Society. Part 2: Intensive Care and Emergency Department. Br J Anaesth. 2011;106: 632-42.

7. Williams PL. Gray's Anatomy: 38th Edition. Churchill Livingstone, 1995, p. 1637.

8. Michaels L. Pathology of the larynx. London: Springer, 1984, pp. 47-50.

9. Fleisher LA. Evidence-Based Practice of Anesthesiology EvidenceBased Practice of Anesthesiology, E-Book, 3rd Edition. Saunders, 2013, pp. 113.
10. Ovassapian A, Dykes MH, Golmon ME. A training programme for fiberoptic nasotracheal intubation. Use of model and live patients. Anaesthesia 1983;38(8):795-8.

11. Johnson C, Roberts JT. Clinical competence in the performance of fiberoptic laryngoscopy and endotracheal intubation: A study of resident instruction. J Clin Anesth. 1989;1(5):344-9.

12. Cole AF, Mallon JS, Rolbin SH, Ananthanarayan C. Fiberoptic intubation using anesthetized, paralyzed, apneic patients. Results of a resident training program. Anesthesiology 1996;84(5):1101-6.

13. Erb T, Hampl KF, Schurch M, Kern CG, Marsch SC. Teaching the use of fiberoptic intubation in anesthetized, spontaneously breathing patients. Anesth Analg. 1999;89(5):1292-5.

14. Heidegger T, Gerig HJ, Ulrich B, Kreienbuhl G. Validation of a simple algorithm for tracheal intubation: Daily practice is the key to success in emergencies - an analysis of 13,248 intubations. Anesth Analg. 2001;92(2):517-22.

15. Hakala P, Randell T, Valli H. Comparison between tracheal tubes for orotracheal fiberoptic intubation. Br J Anaesth. 1999;82(1):135-6.

16. Rosenblatt W. The fiberoptic training jig. Anaesthesia. 2007;62(2):201-2.

17. Mason RA. Learning fiberoptic intubation: Fundamental problems (editorial). Anaesthesia 1992;47:729-31.

18. Schaefer HG, Marsch SCU, Keller HL, Strebel S, Anselmi L, Drewe J. Teaching fiberoptic intubation in anaesthetised patients. Anaesthesia. 1994;49:331-4.

19. Schaefer H-G, Marsch SCU. Comparison of orthodox with fiberoptic orotracheal intubation under total i.v. anaesthesia. $\mathrm{Br} J$ Anaesth. 1991;66:608-10.

Conflict of interest: none declared Financial support: none declared 